Leading Better Sex Lives: Trait Charisma is Associated with Higher Sexual Desire and Satisfaction in Romantic Relationships

\author{
Eric $\mathrm{Tu}^{1}$, Stephanie Raposo ${ }^{1}$, and Amy Muise ${ }^{1}$ \\ ${ }^{1}$ Department of Psychology, York University, Toronto, ON, Canada
}




\begin{abstract}
Sexuality is a key predictor of relationship satisfaction, but sexual desire and satisfaction can be difficult to maintain over time. Limited research informs who might be more likely to experience higher (compared to lower) levels of desire and sexual satisfaction in their relationships. Certain aspects of personality, such as extraversion, have been associated with sexual satisfaction and desire, but evidence linking personality to sexual outcomes has generally been mixed. A promising, yet unexplored, trait that could be linked to desire and sexual satisfaction is charisma - a combination of influence and affability that has been identified as a desirable trait when people are selecting a romantic or sexual partner. Across two studies - a cross-sectional study of individuals in relationships $(N=413)$ and a 21-day dyadic daily experience study $(N=$ 121 couples)_- people higher in charisma reported being more communally responsive to their partner's needs during sex, and in turn, experience higher daily sexual desire and satisfaction. Through higher sexual communal motivation, people with a charismatic partner also reported higher sexual desire, but not sexual satisfaction. The effects were retained above and beyond general communal motivation and Big Five personality dimensions, although extraversion accounted for some of the associations. Therefore, charisma is a trait that is linked with higher sexual communal motivation, which is associated with charismatic people reporting higher desire and sexual satisfaction in their romantic relationships.
\end{abstract}

Keywords: charisma, sexual communal strength, sexual satisfaction, sexual desire 


\section{Leading Better Sex Lives: Trait Charisma is Associated with Higher Sexual Desire and Satisfaction in Romantic Relationships}

Satisfying romantic relationships are one of the strongest predictors of happiness and life satisfaction (Coombs, 1991; Diener \& Seligman, 2002) and sexual desire and satisfaction can be important aspects of maintaining overall relationship satisfaction (Butzer \& Campbell, 2008; Impett et al., 2008; McNulty et al., 2016). However, on average, couples experience lower sexual desire and sexual satisfaction over time (Impett et al., 2014; Klusman, 2002; Schmiedeberg \& Schroder, 2016), and a lack of interest in, or enjoyment of, sex are cited as reasons for ending a relationship (Regan, 2000; Sprecher, 1994; Sprecher, 2002; Yabiku et al., 2009). Despite these declines, some couples maintain desire and satisfaction decades into a relationship (Acevedo \& Aron, 2009). Investigating how individual differences are associated with sexual desire and satisfaction in relationships may be important in understanding how couples can maintain desire and satisfaction, however the results of past research have been mixed. For example, some research has found that Big Five personality dimensions, such as extraversion, are associated with higher sexual satisfaction and desire, but these associations have been inconsistent in other studies (Allen \& Desille, 2007; Costa et al., 1992; Fisher \& McNulty, 2008; Heaven et al., 2000; Kurpisz et al., 2016; Shafer, 2001). Overall, limited work informs who may be better able to maintain sexual desire and satisfaction in romantic relationships. One individual difference in particular that has yet to be explored in the context of romantic relationships but may play a unique role in the maintenance of sexual desire and satisfaction, is charisma - the quality of being influential and likeable.

\section{Charisma}


Charisma has primarily been investigated in the context of leadership and workplace interactions. Leaders high in charisma are typically described as inspiring, tend to communicate their vision effectively, and motivate others toward a common goal (House 1977; Weber, 1922). They also promote higher performance (Balkundi et al., 2011; Bass, 1985; Nohe et al., 2013), greater job satisfaction (Ezez et al., 2008; Shamir et al., 1993; Vlachos et al., 2013), and lower levels of aggression (Hepworth \& Towler, 2004) among their colleagues. Charismatic people tend to make others feel comfortable, fostering more positive and less negative affect (Ezez et al., 2008), and can inspire change and innovation (Paulsen et al., 2009). The bulk of research on trait charisma has focused on leaders in organizational contexts and the outcomes for their colleagues or employees, yet the role of charisma in other contexts, such as romantic relationships, is not well understood.

When investigated outside of leadership and workplace contexts, general charisma is described as a mix of influence and affability. That is, in everyday life, charismatic people tend to have a strong presence in a room and the ability to lead a group, as well as being approachable and displaying positive affect (Tskhay et al., 2018). Research using this definition of charisma has found that charisma is observable in others - people who self-report as being charismatic are also seen as charismatic by others (Tskhay et al., 2018). Charisma is also shown to be distinct from other individual differences, such as extraversion and agreeableness, and charismatic people are perceived as likable and persuasive (Tskhay et al., 2018). Although charisma has been associated with aspects of negative traits, such as narcissism, research suggests that charismatic people might present as confident and self-assured like those high in narcissism, but charisma is distinct from the antagonistic or defensive features of narcissism (Rogoza \& Fatfouta, 2020). Although initial work has documented correlates of charisma outside of work-related contexts, it 
is not yet known how charismatic people experience more intimate interactions, such as those with a romantic partner.

\section{Charisma and sexuality in relationships}

Although no previous work has investigated whether being charismatic or having a charismatic partner helps people maintain desire and sexual satisfaction, recent work has begun to provide insight into the association between charisma and sexuality. Specifically, only one study to our knowledge has considered the role of charisma in the desirability of a sexual or relational partner. In a study exploring partner preferences for short or long-term partners, when men and women were asked what qualities they preferred in a partner for a one-night stand, one of the most important qualities was charisma, and for men, charisma was also one of the most important qualities when seeking a long-term partner (Flegr et al., 2019). These initial findings suggest that charismatic people are at least perceived by potential partners to have sexual prowess, and people report higher desire for a charismatic partner. However, it is unclear the extent to which charismatic people (and their partners) report greater desire for sex, or more satisfying sexual experiences, in the context of an ongoing relationship.

The bulk of the previous research that we draw on to support our claim that charisma is associated with sexual desire and satisfaction is from findings about charisma in other, broader contexts. Charismatic leaders tend to be happier, report greater life satisfaction (Nassif et al., 2020), and have more positive interactions with others, in part because they are seen as effective and attractive (Bono \& Ilies, 2006). In workplace contexts, charismatic people are also described as passionate and report greater enthusiasm and enjoyment in their work (Ho \& Astakhova, 2020; Vallerand, 2015). High levels of work passion in charismatic leaders are also associated with colleagues feeling more passionate about their work (Ho \& Astakhova, 2020), as well as 
more positive impacts on work attitudes, behaviors, well-being (Vallerand et al., 2014), relationship quality with colleagues (Philippe et al., 2010), and job and life satisfaction (Ho \& Astakhova, 2020). If features of a charismatic personality involve passionate engagement with important aspects of life and the ability to inspire and excite others (Conger \& Kanungo, 1998), it is possible that charismatic people also report higher sexual desire and satisfaction in their intimate relationships.

\section{The Role of Sexual Communal Motivation}

One reason why charismatic people might report higher sexual desire and satisfaction is due to their communal motivation to meet the needs of others. Indeed, people who are charismatic often aim to understand the needs of others and may be particularly skilled at intuiting other people's needs or interests. For example, charismatic leaders focus their attention on issues that are important to colleagues (Pillai et al., 2003), are more empathetic, and pay more attention to their colleagues' needs to encourage personal development (Bass, 1985). Related to their communal approach with others, charismatic people tend to promote a collective identity among their colleagues — that is, a bond that makes their colleagues feel unified and acknowledges each members distinct strengths (Conger et al., 1998; House \& Howell, 1992; Shamir et al., 1993). Communal relationships consist of members feeling a responsibility for meeting each other's needs and providing benefits to one another noncontingently (Clark \& Mills, 1979). When colleagues feel they have a shared identity (i.e., when their relationship is communal in nature), this can increase collective endeavors that will be favoured over selfinterests (Meindl \& Lerner, 1983). Placing an emphasis on a collective identity in the workplace can also lead to greater commitment to the group's values and effort toward tasks (Salancik, 1977; Shamir et al., 1993). In romantic relationships, valuing a collective identity may allow 
partners to feel more committed toward one another, which is an important component of maintaining relationship and sexual satisfaction (Duffy \& Rusbult, 1986; Sprecher, 2002).

Although the association between charisma and communal motivation has primarily been investigated in the context of building a collective identity among work colleagues, communal motivation is a particularly important factor in the quality of sexual relationships. Communal motivation in the specific domain of sexuality, or sexual communal strength, is the motivation to be responsive to a partner's sexual needs (Muise et al., 2013; Muise \& Impett, 2016). Broadly, past research has found that people higher, compared to lower, in sexual communal strength report higher sexual desire and satisfaction, and are better able to maintain their sexual desire over time (Muise \& Impett, 2015; Muise et al., 2013). People higher sexual communal strength also tend to be more likely to engage in sex with their partner even when they are not in the mood and are more openminded to their partner's preferences (Muise \& Impett, 2015). In turn, their partners report greater relationship and sexual satisfaction, desire, and commitment (Muise \& Impett, 2015; Muise et al., 2013).

Given that charismatic people emphasize a collective identity (House \& Howell, 1992; Shamir et al., 1993) and are able to intuit other people's needs (Bass, 1985; Pillai et al., 2003), charismatic people may also be more partner-focused in their sexual relationships. Although it is likely that charismatic people will generally be more communal in their relationships, given that charismatic people are seen as desirable sexual partners (Flegr et al., 2019) and tend to be passionate in other domains (Ho \& Astakhova, 2020), they may be particularly likely to be communal in the sexual domain of relationships, above and beyond their general communal tendencies. In turn, higher sexual communal strength should then be associated with higher desire and sexual satisfaction for charismatic people and their partners. 


\section{The Current Study}

Across two studies, we aim to explore whether charismatic people report higher sexual desire and sexual satisfaction in the context of romantic relationships. In our first study, we conducted a preregistered (https://osf.io/5hegp/?view_only=400fe9c64fe84a5e82757886bda69b69) cross-sectional online study as an initial test of the association between charisma, sexual desire, and sexual satisfaction. In this study, we also aimed to rule out alternative explanations for any associations between charisma and sexual quality, such as whether any effects were driven by general communal strength, Big Five personality traits, or narcissism. In our second study, we utilized data from a dyadic daily experience study to replicate our findings from Study 1 in the context of couples' daily lives, and to test whether any associations between charisma and sexual quality extended to the partners of charismatic people. We also tested whether charismatic people are more communal in their daily sexual experiences and if this accounts for the associations with sexual desire and satisfaction.

\section{Study 1}

\section{Participants and Procedures}

First, we conducted a power analysis to inform the sample of our preregistered study. The sample size was based on the smallest effect size from a pilot study which included the key variables of interest (see Supplementary Materials for details and findings of the pilot study). To detect a small effect size with an $\alpha=.05$, and $95 \%$ power, we needed a sample of 353 people. ${ }^{1}$ However, we oversampled to account for attrition and inattentive responding. We initially recruited 453 people, but 40 were removed for not meeting eligibility criteria or for completing 
less than $70 \%$ of the survey. Our final sample included 413 people in relationships (see Table 1 for more detailed demographic information).

We recruited participants using Prolific, an online recruitment website (https://www.prolific.co/). Eligibility criteria for the study included being at least 18 years of age, in a romantic relationship, and currently residing in Canada, the United States, or the United Kingdom. If participants were eligible and interested in participating in the study, they were given a link to the online Qualtrics survey that took approximately 30-minutes to complete. Participants were compensated the equivalent of \$2.85 CAD (\$2.19 USD, £1.67 GBP) for their participation in the study.

\section{Measures}

In addition to our measures of interest, participants reported on other demographics such as their age, gender, relationship duration, relationship status, ethnicity, and sexual orientation. See Table 2 for correlations, means and standard deviations of our main demographics and measures of interest. We report the reliability of our measures below using two indicators, alpha ( $\alpha$; Cronbach, 1951) and omega ( $\Omega$; McDonald, 1999).

Charisma. Charisma was assessed using the General Charisma Inventory which includes six items measured on a 5-point Likert scale (1 = "Strongly disagree" to 5 = "Strongly agree") (Tskhay et al., 2018). The measure is composed of two subscales each with three itemsinfluence (e.g., "Has the ability to influence people") and affability (e.g., "Makes people feel comfortable"). We assessed people's own self-reported charisma $(\alpha=.78, C I[.733, .806], \Omega=$ $.78, C I[.730, .812])$, as well as their perceptions of their partner's charisma $(\alpha=.96, C I[.943$, $.964], \Omega=.96, C I[.945, .966])$. 
Sexual Satisfaction. Sexual satisfaction was assessed using the Global Measure of Sexual Satisfaction (Lawrence \& Byers, 1998). Participants responded to five 7-point bipolar items about their sexual relationship: "bad" to "good", "unpleasant" to "pleasant", "negative" to "positive", "unsatisfying" to "satisfying", and "worthless" to "valuable" $(\alpha=.86, C I[.835, .878]$, $\Omega=.86, C I[.831, .878])$.

Sexual Desire. Sexual desire was measured using two items assessing a person's level of sexual desire over the last four weeks. Items include: "Over the past 4 weeks, how often did you feel sexual desire or interest for your partner?" ( $1=$ "Almost never or never" to $5=$ "Almost always or always") and "Over the past 4 weeks, how would you rate your level (degree) of sexual desire or interest?" ( $1=$ "Very low or none at all" to $5=$ "Very high"; $\alpha=.87, C I[.831$, $.901], \Omega=.88, C I[.829, .902])$.

Communal Strength. Communal strength was measured using the 10-item Communal Strength Scale (Mills et al., 2004). Items are rated on an 11-point Likert scale $(0=$ "Not at all" to $10=$ "Extremely") and include: "How far would you be willing to go to visit your partner?" $(\alpha=$ $.89, C I[.875, .911], \Omega=.89, \operatorname{CI}[.871, .909])$

Sexual Communal Strength. Sexual communal strength was measured using the 6-item Sexual Communal Strength Scale (Muise et al., 2013). Items are rated on a 5-point Likert scale $(0=$ "Not at all", 4 = "Extremely") and include: "How far would you be willing to go to meet your partner's sexual needs?" $(\alpha=.81, C I[.767, .842], \Omega=.81, C I[.767, .842])$, and there are two reverse-scored items.

Big Five Personality. The Big Five personality dimensions were measured using the Big Five Inventory-2 (Soto \& John, 2017). This measure includes five subscales with 12 items each assessing extraversion (e.g., "Is outgoing, sociable," $\alpha=.86, C I[.835, .878], \Omega=.86, C I[.831$, 
.878]), agreeableness (e.g., "“Is compassionate, has a soft heart," $\alpha=.8, C I[.768, .829], \Omega=.8$,

$C I[.766, .83]$ ), conscientiousness (e.g., "Is dependable, steady," $\alpha=.88, C I[.857, .895], \Omega=.88$, $C I[.863, .898]$ ), negative emotionality (e.g., "Is moody, has up and down mood swings," $\alpha=.92$, $C I[.913, .935], \Omega=.93, C I[.914, .937])$, and open-mindedness (e.g., "Is curious about many different things," $\alpha=.87, C I[.848, .886], \Omega=.87, C I[.848, .888])$. All items are measured on a 5-point Likert scale (1 = "Disagree strongly", 5 = "Agree strongly"). Additionally, each of these five subscales are composed of three additional facets; however, these were not explored in our analyses.

\section{Data Analyses}

Data and syntax for all analyses are available on the Open Science Framework: https://osf.io/5hegp/?view_only=400fe9c64fe84a5e82757886bda69b69. The data were analyzed using RStudio Version 1.2.5033 (R Core Team, 2018). Data cleaning procedures (e.g., removing blank or ineligible responses and compiling items into a composite measure) were done using the dplyr package (Wickham et al., 2019). Means and standard deviations were calculated using the psych package (Revelle, 2018), while alpha and omega reliability coefficients were calculated using the MBESS package with a bootstrapping technique of 5000 bootstrapped resamples to get a coefficient estimate and 95\% confidence intervals (Kelley, 2019). The data were analyzed using simple and multiple linear regression models. We focused on the associations between self-reported charisma and sexual satisfaction and desire, but we also tested whether perceptions of a partner's charisma were associated with sexual satisfaction and desire. Furthermore, we tested whether self-reported charisma was associated with sexual communal strength. Additionally, we conducted multiple linear regression models of self-reported charisma predicting sexual communal strength while controlling for communal strength and the Big Five 
personality measures. For all of the analyses, we report the unstandardized coefficients $(b)$.

Although we did not have predictions about the role of gender in our findings, we tested whether any effects were moderated by gender in an exploratory manner. Past research suggests women are typically more warm and pleasant, which is more consistent with the affability component of charisma, while men are expected to be more emotionally neutral (Bem, 1981; Carlson, 1971; Keating, 2011). Furthermore, charismatic leadership styles tend to be more common among women (Carli, 1999; Costrich et al., 1975; Eagly \& Karau, 2002), thus it is possible that there are gender differences in the associations between charisma and sexual quality. However, we tested for gender difference and there was no consistent pattern for men and women (see Supplement for details).

\section{Results}

We preregistered our key analyses of the associations between charisma and sexual desire and satisfaction, including controlling for the Big Five (https://osf.io/5hegp/?view_only=400fe9c64fe84a5e82757886bda69b69). First, we tested whether people higher in charisma (and those who perceive their partner as more charismatic) report higher sexual satisfaction and desire. Indeed, higher charisma was associated with greater sexual satisfaction, $b=.048, S E=.016, t=2.997, p<.01, C I[.016, .079]$, and sexual desire, $b=$ $.045, S E=.013, t=3.464, p<.001, C I[.019, .071]$. In addition, after accounting for a person's reports of their own charisma, the extent to which they perceive their partner as charismatic was associated with greater sexual satisfaction, $b=.082, S E=.014, t=5.754, p<.001, C I[.054$, $.110]$ and sexual desire, $b=.054, S E=.012, t=4.690, p<.001, C I[.031, .077]$.

We also explored whether one of the reasons charismatic people had more satisfying sex lives and greater desire was that they are more sexually communal. We found that higher 
charisma was associated with greater sexual communal strength, $b=.037, S E=.008, t=4.438, p$ $<.001, C I[.021, .053]$. We also tested whether the association between charisma and sexual communal strength remained significant above and beyond general communal strength. Indeed, when we conducted a multiple linear regression model controlling for general communal strength, which was significantly associated with charisma $(b=.043, S E=.016, t=2.611, p<$ $.01, C I[.011, .075])$, the significant positive association between charisma and sexual communal strength remained significant, $b=.027, S E=.008, t=3.623, p<.001, C I[.012, .042]$.

\section{Ruling out Alternative Explanations}

Next, we tested whether associations between charisma and sexual communal strength, desire and satisfaction remained significant after accounting for the Big Five personality dimensions. Past research has suggested mixed evidence for the association between personality dimensions (e.g., extraversion) and sexuality outcomes (e.g., Allen \& Desille, 2007; Costa et al., 1992), and charisma has also been shown to be correlated with some of these personality dimensions, namely extraversion and agreeableness (Tskhay et al., 2018). Therefore, it is important to test whether charisma uniquely influences sexuality outcomes above and beyond other individual difference measures.

In fact, all of the associations between charisma and sexual communal strength remained significant after accounting for the Big Five personality dimensions (see Supplement for details). When predicting sexual satisfaction and desire, all of the associations with charisma remained significant while controlling for the Big Five personality dimensions (see Supplement for details) with two exceptions. Controlling for extraversion, the association between charisma and sexual satisfaction, $b=.028, S E=.022, t=1.276, p=.203, C I[-.015, .072]$ and sexual desire, $b=.032$, $S E=.019, t=1.693, p=.091, C I[-5.193, .070]$ were reduced to non-significant. Specifically, 
extraversion was significantly associated with higher sexual satisfaction $(b=.038, S E=.007, t=$ 4.938, $p<.001, C I[.023, .053])$, and desire, $b=.018, S E=.009, t=1.970, p<.05, C I[.004$, .030], which accounted for the effects of charisma on sexual satisfaction and desire. However, the association between charisma and sexual communal strength remains significant, $b=.025$, $S E=.012, t=2.127, p<.05, C I[.002, .047]$, while controlling for extraversion, $b=.009, S E=$ $.006, t=1.542, p=.124, C I[-.002, .019]$. Although not part of our pre-registration, we also tested whether charisma remained significantly associated with sexual desire and satisfaction after accounting for their comfort with closeness and independence in relationships (i.e., their attachment anxiety and avoidance) and narcissism. The associations between charisma and sexual desire and satisfaction held while controlling for attachment anxiety and avoidance (with one exception for avoidance), and narcissism (see Supplement for details).

\section{Study 2}

Study 1 provided initial evidence for an association between a person's own charisma and their perceptions of partner's charisma and sexual satisfaction and desire. In addition, in Study 1, charismatic people reported higher sexual communal strength, above and beyond general communal strength in their relationship. Largely, these associations remained significant after accounting for other individual difference variables (Big 5 personality traits, narcissism, attachment). In Study 2-a 21-day dyadic daily experience study—we aimed to replicate our findings that charisma was associated with sexual satisfaction and desire in couples' daily lives, as well as extend our findings by exploring whether one's own charisma was associated with a partner's sexual satisfaction and desire. In addition, we tested whether charisma is associated with greater sexual communal strength and whether the associations between charisma and sexual satisfaction and desire were mediated by sexual communal strength. 


\section{Participants and Procedures}

Participants were recruited using online (e.g., Facebook, Reddit, Craigslist, Twitter, Kijiji) and physical advertisements (i.e., flyers). To be eligible for the study, participants had to be at least 18 years of age, living together, in a relationship for at least two years, currently sexually active in their relationship, living in Canada or the United States, able to read and understand English, and have daily access to a computer with Internet. Couples interested in participating in the study were sent a pre-screening survey via email to ensure they met the eligibility criteria. We then followed up with both partners over the phone. The telephone screening confirmed the eligibility criteria, and asked questions (e.g., when they met, each other's birthdays) to confirm their couple status and authentic responding. Once eligible for participation in the study, participants were emailed a link to the background survey hosted on Qualtrics. Completion of the background survey by both members initiated the start of the 21day daily experience study. Participants were compensated up to \$60 CAD (\$48 USD) for their participation in the study. Our final sample included 121 couples (see Table 1 for more detailed demographic information).

\section{Measures}

Given the dyadic nature of the data, self-reports and partner reports were available for each measure. Similar to our first study, in addition to our measures of interest, both partners reported on other demographic characteristics such as their age, gender, relationship duration, relationship status, ethnicity, and sexual orientation. For the daily measures, we used shortened scales to measure our constructs of interest to minimize participant attrition (Bolger et al., 2003). See Table 3 for correlations, means and standard deviations of our main demographics and measures of interest. Since we utilized previously collected data from a larger study, we do not 
have additional individual difference measures (e.g., Big Five Personality, narcissism) in Study 2 to test as covariates.

Charisma. Charisma was measured using the same scale as Study 1 and only at background ( $\alpha=.83, C I[.781, .863], \Omega=.82, C I[.763, .862])$.

\section{Daily-Level Measures}

Sexual Satisfaction. Sexual satisfaction was measured using the same scale as Study 1, but it was adapted to be about that day $(\Omega=.98, C I[.984, .987])$

Sexual Desire. Sexual desire was measured with one item on a 7-point Likert scale $(1=$ Strongly disagree to 7 = Strongly agree). The item was "Today, I felt a great deal of sexual desire for my partner".

Sexual Communal Strength. Sexual communal strength was only measured on sex days using a 3-item measure about a person's communal motivation to meet a partner's needs during sex. Items were rated on a 7 -point Likert scale ( $1=$ Strongly disagree, $7=$ Strongly agree $)$ and included: "During sex, I was focused on meeting my partner's needs" $(\Omega=.81, C I[.776, .834])$.

\section{Data Analysis}

The data from Study 2 were part of a larger 21-day dyadic daily diary study (https://osf.io/5hegp/?view_only=400fe9c64fe84a5e82757886bda69b69). We used reports of charisma at background to predict sexuality outcomes at the daily level. The data were also analyzed using R Studio, using the same packages from Study 1 to clean the data and calculate means, standard deviations and scale reliability coefficients. We tested our key predictions using multilevel modeling guided by the Actor-Partner Interdependence Model (APIM; Kenny et al., 2006) in R using the nlme package (Pinheiro et al., 2018). We aimed to assess whether a person's own, and their partner's, charisma were associated with daily sexual satisfaction and 
desire. Additionally, we conducted a multilevel APIM mediation model using the Monte Carlo Method for Assessing Mediation to explore whether the associations between charisma and sexual satisfaction and desire were mediated by sexual communal strength (Selig \& Preacher, 2008). Similar to our previous study, we did not have predictions about the role of gender in our findings, however past research suggests women may more likely be perceived as charismatic than men (Bem, 1981; Carli, 1999; Carlson, 1971; Costrich et al., 1975; Eagly \& Karau, 2002; Keating, 2011), so we tested whether any effects were moderated by gender in an exploratory manner. However, there was no consistent pattern of gender differences and most of the effects were consistent for men and women (see Supplement for details).

\section{Results}

First, we aimed to replicate the findings from Study 1 and tested whether charisma is associated with higher sexual desire and satisfaction in daily life. We found that people higher in charisma reported greater sexual satisfaction, $b=.044, S E=.02, t=2.233, p<.05, C I[.006$, .083]; however, the association between charisma and sexual desire did not reach significance, $b$ $=.028, S E=.017, t=1.642, p=.102, C I[-.005, .061]$. In Study 2 we were able to test partner effects, however there were no significant associations between having a charismatic partner and sexual satisfaction, $b=.019, S E=.02, t=.935, p=.351, C I[-.020, .058]$, or sexual desire, $b=$ $.017, S E=.017, t=.979, p=.329, C I[-.017, .050]$.

Next, we explored whether there is an indirect effect of being charismatic on both partners' sexual satisfaction through higher sexual communal strength. In other words, we tested the role of sexual communal strength as a mediator of the associations between a person's charisma and both partners' sexual quality. First, we found that people higher in charisma report being more communal during sex over the course of the 21-day study, $b=.043, S E=.014, t=$ 
$3.157, p<.01, C I[.017, .07]$; however, being charismatic was not related to partner's sexual communal strength, $b=.021, S E=.014, t=1.523, p=.129, C I[-.006, .048]$. The results revealed a significant indirect effect of being charismatic and reporting higher daily sexual satisfaction through the charismatic person being more communal during sex, $C I[.0002, .002]$; however, there was no significant indirect effect of charisma on a partner's daily sexual satisfaction through the charismatic person being more communal during sex, $C I[-.0002, .001]$. The results also revealed a significant indirect effect of being charismatic on one's own daily sexual desire through being more communal during sex, $C I[.0007, .003]$, and a significant indirect effect on partner's daily sexual desire through the charismatic person's higher sexual communal strength, $C I[.0004, .003]$. Thus, people higher in charisma were more motivated to meet their partner's needs during sex and in turn, they report higher daily sexual satisfaction and both they and their partner report higher sexual desire.

\section{Discussion}

The current findings shed light on how being charismatic is associated with sexual desire and satisfaction in romantic relationships, which are key components of maintaining overall romantic relationship quality (Butzer \& Campbell, 2008; Chau et al., 2011; Impett, Strachman, et al., 2008). Past research has found that charismatic people tend to be more communally oriented (Bass, 1985; Pillai et al., 2003) and passionate in workplace contexts (Ho \& Astakhova, 2020), allowing for greater job and life satisfaction for both themselves (Nassif et al., 2020) and their colleagues (Ezez et al., 2008; Shamir et al., 1993; Vlachos et al., 2013). However, the current set of studies are the first to our knowledge to investigate the romantic relationships of charismatic people. By understanding the individual differences associated with people reporting higher 
desire and more satisfying sex lives, we hope to add to the literature on maintaining sexual quality in romantic relationships.

Across both studies, charismatic people reported higher sexual satisfaction and desire, and, in Study 1, those who perceived their partner to be charismatic also reported higher sexual satisfaction and desire. However, in Study 1, the associations between charisma and sexual desire and satisfaction were reduced when we accounted for extraversion. Past research has found charisma to be moderately correlated with extraversion (Tskhay et al., 2018), and both traits are assessed by asking about positivity and social adaptability. Some past research has found an association between extraversion and sexual satisfaction (Allen \& Desille, 2017), as well as with greater frequency of sex (Kurpisz et al., 2016). Since the influential qualities of charismatic people, such as having a presence in a room and being able to lead a group, can overlap with extraverted qualities of being outgoing and assertive, it is not entirely surprising that extraversion has accounted for the association between charisma and sexual satisfaction. However, the association between charisma and sexual communal strength remained significant when accounting for extraversion (which was not significantly associated with sexual communal strength) suggesting that being communally motivated to meet a partner's sex needs might be a unique pathway through which charisma is associated with sexual desire and satisfaction. That is, although extraversion accounted for the association of charisma and sexual satisfaction and desire in Study 1, charisma is uniquely associated with sexual communal strength, which is indirectly linked to higher sexual desire and satisfaction.

Given that charismatic people have been described as more communally oriented in a workplace setting through their emphasis on a collective identity (House \& Howell, 1992; Shamir et al., 1993) and focus on other people's needs (Bass, 1985; Pillai et al., 2003), we 
suspected that charismatic people would be more communal in their romantic relationships, as well. More specifically, charismatic are often viewed as passionate (Ho \& Astakhova, 2020) and desirable (Flegr et al., 2019), so we believed that charismatic people might be particularly likely to be high in sexual communal strength in their relationships. In fact, our studies revealed that charisma was associated with higher sexual communal strength, and this was true above and beyond general communal motivation. Past research has found that people who are more communal during sex report greater sexual satisfaction and desire, and these benefits also extended to their partners (Muise \& Impett, 2015; Muise et al., 2013). We find that people who are more communal during sex report greater sexual satisfaction and desire, and also have partners who report greater sexual desire. In fact, our results suggest that one of the reasons why charismatic people report more sexual satisfaction and desire in their romantic relationships is because they tend to be more communally focused on meeting their partner's needs during sex. Additionally, although we did not find that being charismatic directly impacted a partner's sexual desire, we found that through charismatic people being more communal during sex, their partners also report greater sexual desire. These results suggest that one of the reasons charismatic people and their partner report greater sexual desire and satisfaction is through being more communal during sex.

One of the reasons why charismatic people are more communal during sex may be due to their perspective-taking ability. For instance, past research suggests charismatic people possess greater empathy and a more individualized consideration for their colleagues (Bass, 1985). Charismatic people have been found to display frequent support for their colleagues' efforts (Avolio \& Bass, 1985), and are concerned with their colleagues' feelings and needs (Pilai et al., 2003; Podsakoff et al., 1990). Given that charismatic people focus on a collective identity 
(House \& Howell, 1992; Shamir et al., 1993) and the concerns of others (Podsakoff et al., 1990), charismatic people may feel rewarded through other people's fulfilment and this may explain charismatic people's motivation to satisfy their partner's sexual needs in their romantic relationships.

\section{Limitations and Future Directions}

Although the current work provides preliminary evidence that charismatic people and their partners may experience more satisfying sexual lives in their romantic relationships, and that this is at least partially due to charismatic people being more communal during sex, there are limitations to the current research. Although in Study 1 we found that perceiving a partner as charismatic was consistently associated with sexual desire and satisfaction, in our dyadic study (Study 2), there were limited partner effects (i.e., only an indirect effect to a partner's sexual desire through sexual communal strength). This raises the question of how accurate people are in perceiving their partner's charisma, and whether they tend to perceive their partner as more charismatic than the partner themselves reports. It is possible that a direct association between a person's charisma and their partner's sexual quality is more dependent on whether their partner perceives them to be charismatic, rather than on their self-reported charisma. On the other hand, we do find an indirect association between a person's charisma and their partner's sexual desire, which may be due to the beneficial behaviors charismatic people practice (e.g., communal during sex) that are not dependent on partner's perceptions of their charisma. Future work should test how accurate or biased people are in perceiving their partner's charisma and consider how accuracy and bias in perceptions are associated with sexual and relationship outcomes above and beyond the effects of charisma. 
Although our studies include replicated results to bolster support for the association between charisma and sexual satisfaction and desire, the results are correlational and cannot confirm the causal direction of the association. Since there is past research that suggests the Big Five personality dimensions, which are correlated with charisma, are fairly stable over time (Vaidya et al., 2002; Roberts and DelVecchio, 2000; Specht et al., 2011), it is likely that charisma is a relatively stable trait. Therefore, a person's charisma likely precedes their sexual quality in a particular relationship. Past research investigating charisma, however, suggests it is possible to increase charisma in leaders through training (Antonakis et al., 2011), and, although the conceptualization of charisma differs in workplace contexts, it may be possible to manipulate the charisma of people in romantic relationships to test whether increases in charisma have consequences for sexual satisfaction, desire, and sexual communal strength.

Charisma has been found to be a desirable quality when seeking a short-term partner (Flegr et al., 2019), and in the current research we also demonstrate that it is associated with higher desire and sexual satisfaction in established relationships. However, it remains unclear how charisma influences the development of relationships and the maintenance of sexual desire and satisfaction over time. Future research could recruit new couples and follow them over time in their relationship to test how charisma is associated with sexual quality early on in relationships and if charismatic people and their partners are more likely to maintain desire and satisfaction over time. In addition, a longitudinal design would allow the exploration of other mechanisms that might account for why charismatic people may have more satisfying sex lives, such as whether they are more skilled communicators about sexual topics.

\section{Conclusion}


The results of the current set of studies extend past research on charisma by providing preliminary evidence that trait charisma is associated with sexual quality in romantic relationships. Extensive research on charisma in workplace contexts has found many benefits for charismatic people and their colleagues (Balkundi et al., 2011; Bass, 1985; Ezez et al., 2008; Hepworth \& Towler, 2004; Nohe et al., 2013; Paulsen et al., 2009; Shamir et al., 1993; Vlachos et al., 2013); however, to our knowledge, only one other study has documented the closest relationships of charismatic people. Our results suggest that charisma is associated with greater sexual satisfaction and desire in romantic relationships, and this is, in part, due to their more communal approach to their sexual relationship. Although past research shows significant benefits for colleagues of charismatic people (e.g., Balkundi et al., 2011; Bass, 1985), our findings suggest that in romantic relationships it may be more important to perceive one's partner as charismatic rather than whether one's partner self-reports as charismatic. The current studies are the first to our knowledge to explore trait charisma in romantic relationships, and we hope this work will encourage more research on charisma by highlighting that trait charisma that can uniquely predict important outcomes in romantic relationships. 


\section{Footnotes}

${ }^{1}$ In Study 1, we intended on oversampling from 353 participants to 390 participants to account for potentially losing participants due to our exclusion criteria. Due to the way Prolific recruits participants, when we closed our study we had 453 submissions. After removing participants due to incompleteness or not meeting our eligibility criteria, the remaining sample was 413 participants. All participants completed at least $70 \%$ of the study, passed attention checks, and were compensated for their participation. We only conducted analyses on the final sample, prior to exclusions. 


\section{References}

Acevedo B. P., \& Aron, A. (2009). Does a long-term relationship kill romantic love? Review of General Psychology, 13(1), 59-65. https://doi.org/10.1037/a0014226

Allen, M. S., \& Desille, A. E. (2017). Personality and sexuality in older adults. Psychology \& Health, 32(7), 843-859. https://doi.org/10.1080/08870446.2017.1307373

Antonakis, J., Fenley, M., \& Liechti, S. (2011). Can charisma be taught? Tests of two interventions. Academy of Management Learning and Education, 10(3), 374-396. https://doi.org/10.5465/amle.2010.0012

Balkundi, P., Kilduff, M., \& Harrison, D. A. (2011). Centrality and charisma: Comparing how leader networks and attributions affect team performance. Journal of Applied Psychology, 96(6), 1209-1222. https://doi.org/10.1037/a0024890

Bass, B. M. (1985). Leadership and Performance Beyond Expectations. Free Press: New York.

Bem, S. L. (1981). Bem Sex-Role Inventory: Professional manual. Palo Alto, CA: Consulting Psychologists Press.

Bolger, N., Davis, A., \& Rafaeli, E. (2003). Diary methods: Capturing life as it is lived. Annual Review of Psychology, 54, 579-616. https://doi.org/10.1146/annurev.psych.54.101601.145030

Bono, J. E., \& Ilies, R. (2006). Charisma, positive emotions and mood contagion. The Leadership Quarterly, 17(4), 317-334. https://doi.org/10.1016/j.leaqua.2006.04.008 
Butzer, B., \& Campbell, L. (2008). Adult attachment, sexual satisfaction, and relationship satisfaction: A study of married couples. Personal Relationships, 15, 141-154. https://doi.org/10.1111/j.1475-6811.2007.00189.x

Carli, L. L. (1999). Gender, interpersonal power, and social influence. Journal of Social Issues, 55, 81-99. https://doi.org/10.1111/0022-4537.00106

Carlson, R. (1971). Sex differences in ego functioning: Exploratory studies of agency and communion. Journal of Consulting and Clinical Psychology, 37, 267-277. https://doi.org/10.1037/h0031947

Clark, M. S., Lemay, Jr. E. P., Graham, S. M., Pataki, S. P., \& Finkel, E. J. (2010). Ways of giving benefits in marriage: Norm use, relationship satisfaction, and attachment-related variability. Psychological Science, 21, 944-951. https://doi.org/10.1177/0956797610373882

Conger, J. A., \& Kanungo, R. N. (1998). Charismatic leadership in organizations. Thousand Oaks, CA: Sage.

Conger, J. A., Kanungo, R. N., \& Menon, S. T. (2000). Charismatic leadership and follower effects. Journal of Organizational Behavior, 21(7), 747-767. https://doi.org/10.1002/1099-1379(200011)21:7<747::AID-JOB46>3.0.CO;2-J

Coombs, R. H. (1991). Marital status and personal well-being: A literature review. Family Relations: An Interdisciplinary Journal of Applied Family Studies, 40(1), 97102. https://doi.org/10.2307/585665

Costa, P. T., Fagan, P., \& Wise, T. N. (1992) The five-factor model of personality and sexual functioning in outpatient men and women. Psychiatric Medicine, 10(2), 199-215. 
Costrich, N., Feinstein, J., Kidder, L., Marecek, J., \& Pascale, L. (1975). When stereotypes hurt: Three studies of penalties for sex-role reversals. Journal of Experimental Social Psychology, 11, 520-530. https://doi.org/10.1016/0022-1031(75)90003-7

Cronbach, L. J. (1951). Coefficient alpha and the internal structure of tests. Psychometrika, 16, 297-334. https://doi.org/10.1007/BF02310555

Diener, E. \& Seligman, M. (2002). Very Happy People. Psychological Science, 13(1), 81-84. https://doi.org/10.1111/1467-9280.00415

Duffy, S. M. \& Rusbult, C. E. (1986). Satisfaction and commitment in homosexual and heterosexual relationships. Journal of Homosexuality, 12(2), 1-23. https://doi.org/10.1300/J082v12n02_01

Eagly, A. H., \& Karau, S. J. (2002). Role congruity theory of prejudice toward female leaders. Psychological Review, 109, 573-598. https://doi.org/10.1037/0033-295X.109.3.573

Ezez, A., Misangyi, V. F., Johnson, D. E., LePine, M. A., \& Halverson, K. C. (2008). Stirring the hearts of followers: Charismatic leadership as the transferal of affect. Journal of Applied Psychology, 93(3), 602-616. https://doi.org/10.1037/0021-9010.93.3.602

Fisher, T. D., \& McNulty, J. K. (2008). Neuroticism and marital satisfaction: The mediating role played by the sexual relationship. Journal of Family Psychology, 22(1), 112-122. https://doi.org/10.1037/0893-3200.22.1.112

Flegr, J., Blum, A., Nekola, O., \& Kroupa, S. (2019). What people prefer and what they think they prefer in short- and long-term partners. The effects of the phase of the menstrual cycle, hormonal contraception, pregnancy, and the marital and the parenthood status on partner 
preferences. Evolution and Human Behavior, 40 (1), 112-125.

https://doi.org/10.1016/j.evolhumbehav.2018.09.003

Heaven, P. C. L., Fitzpatrick, J., Craig, F. L., Kelly, P., \& Sebar, G. (2000). Five personality factors and sex: Preliminary findings. Personality and Individual Differences, 28(6), 11331141. https://doi.org/10.1016/S0191-8869(99)00163-4

Hepworth, W., \& Towler, A. (2004). The effects of individual differences and charismatic leadership on workplace aggression. Journal of Occupational Health Psychology, 9(2), 176185. https://doi.org/10.1037/1076-8998.9.2.176

Ho, V. T., \& Astakhova, M. N. (2020). The passion bug: How and when do leaders inspire work passion? Journal of Organizational Behavior, 41(5), 1-21. https://doi.org/10.1002/job.2443

House, R. J. (1977). A 1976 theory of charismatic leadership. In J. G. Hunt \& L. L. Larson (Eds.), Leadership: The cutting edge (pp. 189-207). Carbondale: Southern Illinois: University Press.

House, R. J., \& Howell, J. M. (1992). Personality and charismatic leadership. The Leadership Quarterly, 3(2), 81-108. https://doi.org/10.1016/1048-9843(92)90028-E

Impett, E. A., Muise, A., \& Peragine, D. (2014). Sexuality in the context of relationships. In D. L. Tolman, L. M. Diamond, J. A. Bauermeister, W. H. George, J. G. Pfaus, \& L. M. Ward (Eds.), APA handbooks in psychology. APA handbook of sexuality and psychology, Vol. 1. Person-based approaches (pp. 269-315). American Psychological Association. https://doi.org/10.1037/14193-010 
Impett, E. A., Strachman, A., Finkel, E. J., \& Gable, S. L. (2008). Maintaining sexual desire in intimate relationships: The importance of approach goals. Journal of Personality and Social Psychology, 94(5), 808-823. https://doi.org/10.1037/0022-3514.94.5.808

Jones, D. N., \& Paulhus, D. L. (2014). Introducing the short dark triad (SD3): A brief measure of dark personality traits. Assessment, 21(1), 28-41. https://doi.org/10.1177/1073191113514105

Keating, C. F. (2011). Channelling charisma through face and body status cues. In D. Chadee \& A. Kostic (Eds.), Social psychological dynamics (pp. 93-111). Jamaica, Caribbean: University of West Indies Press.

Kelley, K. (2019). MBESS: The MBESS R package. R package version 4.6.0. $\underline{\text { https://CRAN.R-project.org/package=MBESS }}$

Kenny, D. A., Kashy, D. A., \& Cook, W. L. (2006). Dyadic data analysis. New York: Guilford Press.

Klusmann, D. (2002). Sexual motivation and duration of partnership. Archives of Sexual Behavior, 31(3), 275-287. https://doi.org/10.1023/A:1015205020769

Kurpisz, J., Mak, M. Lew-Starowicz, M., Nowosielski, K., Bienkowski, P., Koawlczyk, R., Misiak, B., Frydecka, D., \& Samochowiec, J. (2016). Personality traits, gender roles and sexual behaviours of young adult males. Annals of General Psychiatry, 15(28), 1-15. https://doi.org/10.1186/s12991-016-0114-2

Lawrance, K. \& Byers. E. S. (1998). Interpersonal exchange model of sexual satisfaction questionnaire. In C. M. Davis, W. L. Yarber, R. Baureman, G. Scheer, \& S. L. Davis (Eds.), 
Sexuality related measures: A compendium ( $2^{\text {nd }}$ ed., pp. 514-519). Thousan Oaks, CA: Gage.

McDonald R. P. (1999). Test theory: A unified treatment. Mahwah, NJ: Lawrence Erlbaum. McNulty, J. K., Wenner, C. A., \& Fisher, T. D. (2016). Longitudinal associations among relationship satisfaction, sexual satisfaction, and frequency of sex in early marriage. Archives of Sexual Behavior, 45, 85-97. https://doi.org/10.1007/s10508-014-0444-6

Meindl, J. R., \& Lerner, M. J. (1983). The heroic motive: Some experimental demonstrations. Journal of Experimental Social Psychology, 19(1), 1-20. https://doi.org/10.1016/0022-1031(83)90002-1

Mills, J., Clark, M. S., Ford., T. E., \& Johnson, M. (2004). Measurement of communal strength, Personal Relationships, 11, 213-230. https://doi.org/10.1111/j.1475-6811.2004.00079.x

Muise, A., \& Impett, E. A. (2015). Good, giving, and game: The relationship benefits of communal sexual responsiveness. Social Psychological \& Personality Science, 6(2), 164172. https://doi.org/10.1177/1948550614553641

Muise, A., \& Impett, E. A. (2016). Applying theories of communal motivation to sexuality. Social and Personality Psychology Compass, 10(8), 455-467. https://doi.org/10.1111/spc3.12261

Muise, A., Impett, E. A., Kogan, A., \& Desmarais, S. (2013). Keeping the spark alive: Being motivated to meet a partner's sexual needs sustains sexual desire in long-term romantic relationships. Social Psychological and Personality Science, 4(3), 267-273. https://doi.org/10.1177/1948550612457185 
Nassif, A. G., Hackett, R. D., Wang, G. (2020). Ethical, virtuous, and charismatic leadership: An examination of differential relationships with follower and leader outcomes. Journal of Business Ethics. https://doi.org/10.1007/s10551-020-04491-8

Nohe, C., Michaelis, B., Menges, J. I., Zhang, Z., \& Sonntag, K. (2013). Charisma and organizational change: A multilevel study of perceived charisma, commitment to change, and team performance. The Leadership Quarterly, 24(2), 378-389. https://doi.org/10.1016/j.leaqua.2013.02.001

Paulsen, N., Maldonado, D., Callan, V. J., \& Ayoko, O. (2009). Charismatic leadership, change and innovation in an R\&D organization. Journal of Organizational Change Management, 22(5), 511-523. https://doi.org/10.1108/09534810910983479

Philippe, F. L., Vallerand, R. J., Houlfort, N., Lavigne, G. L., \& Donahue, E. G. (2010). Passion for an activity and quality of interpersonal relationships: The mediating role of emotions. Journal of Personality and Social Psychology, 98, 917-932. https://doi.org/10.1037/a0018017

Pillai, R., Williams, E. A., Lowe, K. B., \& Jung, D. I. (2003). Personality, transformational leadership, trust, and the 2000 U.S. presidential vote. The Leadership Quarterly, 14(2), 161192. https://doi.org/10.1016/S1048-9843(03)00008-0

Pinheiro, J., Bates, D., DebRoy, S., Sarkar, D., \& R Core Team. (2018). nlme: Linear and nonlinear mixed effects models. R package version 3.1-137. https://CRAN.R-project.org/package=nlme

Prolific. (2014). Retrieved 2019, from https: //www.prolific.co/

R Core Team (2018). R: A language and environment for statistical computing. R Foundation for Statistical Computing, Vienna, Austria. https://www.R-project.org/ 
Regan, P. (2000). The role of sexual desire and sexual activity in dating relationships. Social Behavior and Personality: an international journal, 28(1). 51-59. https://doi.org/10.2224/sbp.2000.28.1.51

Revelle, W. (2018). Psych: procedures for personality and psychological research. R package version 1.8.12. https://CRAN.R-project.org/package=psych

Roberts, B. W., \& DelVecchio, W. F. (2000). The rank-order consistency of personality traits from childhood to old age: A quantitative review of longitudinal studies. Psychological Bulletin, 126, 3-25. https://doi.org/10.1037/0033-2909.126.1.3

Rogoza, R. \& Fatfouta, R. (2020). Decoding the narcissism-charisma link: A facet approach. Personality and Individual Differences, 156, 1-5. https://doi.org/10.1016/j.paid.2019.109774

Schmiedeberg, C., \& Schroder, J. (2016). Does sexual satisfaction change with relationship duration? Archives of Sexual Behavior, 45(1), 99-107. https://doi.org/10.1007/s10508-015-0587-0

Selig, J. P., \& Preacher, K. J. (2008, June). Monte Carlo method for assessing mediation: An interactive tool for creating confidence intervals for indirect effects [Computer software]. Available from http://quantpsy.org/.

Shafer, A. B. (2001). The big five and sexuality trait terms as predictors of relationships and sex. Journal of Research in Personality, 35(3), 313-338. https://doi.org/10.1006/jrpe.2000.2316

Shamir, B., House, R. J., \& Arthur, M. B. (1993). The motivational effects of charismatic leadership: A self-concept based theory. Organization Science, 4(4), 577-594.

Soto, C. J., \& John, O. P. (2017). The next Big Five Inventory (BFI-2): Developing and assessing a hierarchical model with 15 facets to enhance bandwidth, fidelity, and predictive 
power. Journal of Personality and Social Psychology, 113, 117-143.

\section{https://doi.org/10.1037/pspp0000096}

Specht, J., Egloff, B., \& Schmukle, S. C. (2011). Stability and change of personality across the life course: The impact of age and major life events on mean-level and rank-order stability of the big five. Journal of Personality and Social Psychology, 101(4), 862-882. https://doi.org/10.1037/a0024950

Sprecher, S. (1994). Two sides to the breakup of dating relationships. Personal Relationships, 1(3), 199-222. https://doi.org/10.1111/j.1475-6811.1994.tb00062.x

Sprecher, S. (2002). Sexual satisfaction in premarital relationships: Associations with satisfaction, love, commitment, and stability. The Journal of Sex Research, 39(3), 190-196. https://doi.org/10.1080/00224490209552141

Tskhay, K. O., Zhu, R., Zou, C., \& Rule, N. O. (2018). Charisma in everyday life: Conceptualization and validation of the general charisma inventory. Journal of Personality and Social Psychology, 114(1), 131-152. https://doi.org/10.1037/pspp0000159

Vaidya, J. G., Gray, E. K., Haig, J., \& Watson, D. (2002). On the temporal stability of personality: Evidence for differential stability and the role of life experiences. Journal of Personality and Social Psychology, 83(6), 1469-1484. https://doi.org/10.1037//0022-

\section{$\underline{3514.83 .6 .1469}$}

Vallerand, R. J. (2015). The psychology of passion: A dualistic model. New York: Oxford.

Vallerand, R. J., Houlfort, N., \& Forest, J. (2014). Passion for work: Determinants and outcomes.

In M. Gagné (Ed.), The Oxford handbook of work engagement, motivation, and selfdetermination theory (pp. 85-105). Oxford, UK: Oxford University Press. 
Vlachos, P. A., Panagopoulos, N. G., \& Rapp., A. A. (2013). Feeling good by doing good:

Employee CSR-induced attributions, job satisfaction, and the role of charismatic leadership. Journal of Business Ethics, 118(3), 577-588. https://doi.org/10.1007/s10551-012-1590-1

Wei, M., Russell, D. W., Mallinckrodt, B., \& Vogel, D. L. (2007). The experiences in Close Relationship Scale (ECR)-Short Form: Reliability, validity, and factor structure. Journal of Personality Assessment, 88, 187-204. https://doi.org/10.1080/00223890701268041

Wickham, H., Francois, R., Henry, L., \& Muller, K. (2019). dplyr: A grammar of data manipulation. R package version 0.8.3. https://CRAN.R-project.org/package=dplyr

Yabiku, S. T., \& Gager, C. T. (2009). Sexual frequency and the stability of marital and cohabiting unions. Journal of Marriage and Family, 71(4), 983-1000.

https://doi.org/10.1111/j.1741-3737.2009.00648.x

\section{Supplementary Materials}

\section{Exploratory Study}

With a sample of 303 people (164 female, 137 men, 2 trans) from Amazon's Mechanical Turk, we explored whether charisma (measured by the General Charisma Inventory; Tskhay et al., 2018) was associated with various romantic relationship and sex outcomes. Using multiple regression, we found that charisma was associated with greater sexual satisfaction, $b=.28, S E=$ $.08, t=3.278, p<.01, C I[.111, .445]$, and sexual desire, $b=.18, S E=.04, t=5.017, p<.001$, $C I[.108, .249]$. We used the smallest effect size of interest, which was between charisma and sexual satisfaction, to inform the sample of our preregistered replication study. Using G*Power, based on a small effect size $\left(\mathrm{f}^{2}=.0371\right)$, an $\alpha=.05$, and power of $95 \%$,

\section{Big Five Personality Analyses}


We conducted additional analyses controlling for each of the Big Five personality traits in models in which charisma was predicting sexual communal strength, sexual satisfaction and desire. When controlling for extraversion, we see the association between charisma and sexual communal strength remained significant, $b=.025, S E=.012, t=2.127, p<.05, C I[.002, .047]$, while the association between extraversion and sexual communal strength was nonsignificant, $b$ $=.009, S E=.006, t=1.542, p=.124, C I[-.002, .019]$. Furthermore, when controlling for agreeableness, the association between charisma and sexual communal strength remained significant, $b=.033, S E=.009, t=3.746, p<.001, C I[.016, .050]$, while the association with agreeableness was nonsignificant, $b=.007, S E=.005, t=1.403, p=.161, C I[-.003, .017]$. When controlling for conscientiousness, the association between charisma and sexual communal strength remained significant, $b=.037, S E=.008, t=4.339, p<.001, C I[.020, .053]$, while the association with conscientiousness was nonsignificant, $b=.003, S E=.006, t=.396, p=.692$, $C I[-.010, .015]$. Next, when controlling for negative emotionality, the association between charisma and sexual communal strength remained significant, $b=.037, S E=.009, t=4.169, p<$ $.001, C I[.020, .055]$, while the association with negative emotionality was nonsignificant, $b=$ $.0002, S E=.004, t=.059, p=.953, C I[-.007, .007]$. Lastly, while controlling for openness, both the association between charisma and sexual communal strength, $b=.029, S E=.009, t=3.387$, $p<.001, C I[.012, .046]$, and the association between openness and sexual communal strength, $b$ $=.013, S E=.004, t=3.149, p<.01, C I[.005, .022]$, remained significant.

As mentioned in the main analyses, when extraversion was controlled in the model, the association between charisma and sexual satisfaction became nonsignificant, $b=.028, S E=.022$, $t=1.276, p=.203, C I[-.015, .072]$, while the association between extraversion and sexual satisfaction was significant, $b=.028, S E=.011, t=2.669, p<.01, C I[.007, .049]$. The 
association between charisma and sexual satisfaction remained significant, $b=.056, S E=.017, t$ $=3.292, p<.01, C I[.022, .089]$, when controlling for agreeableness, however the association between agreeableness and sexual satisfaction was also significant, $b=.025, S E=.010, t=$ $2.517, p<.05, C I[.005, .044]$. When controlling for conscientiousness, the association between charisma and sexual satisfaction remained significant, $b=.067, S E=.016, t=4.141, p<.001$, $C I[.035, .099]$, while the association with conscientiousness was nonsignificant, $b=.013, S E=$ $.012, t=1.017, p=.31, C I[-.012, .037]$. For negative emotionality, the association between charisma and sexual satisfaction remained significant, $b=.064, S E=.017, t=3.708, p<.001$, $C I[.030, .098]$, while the association between negative emotionality and sexual satisfaction was nonsignificant, $b=-.006, S E=.007, t=-.942, p=.347, C I[-.020, .007]$. Lastly, when controlling for openness the association between charisma and sexual satisfaction remained significant, $b=$ $.072, S E=.017, t=4.251, p<.001, C I[.039, .105]$, while the association between openness and sexual satisfaction was nonsignificant, $b=-.003, S E=.008, t=-.418, p=.677, C I[-.020, .013]$.

When predicting sexual desire, the association with charisma also became nonsignificant, $b=.032, S E=.019, t=1.693, p=.091, C I[-5.193, .070]$, while controlling for the association between extraversion and sexual desire, $b=.018, S E=.009, t=1.970, p<.05$, $C I[.004, .030]$. Furthermore, when controlling for agreeableness, the association between charisma and sexual desire remained significant, $b=.056, S E=.014, t=3.92, p<.001, C I[.028$, $.084]$, and agreeableness was not significantly associated with sexual desire, $b=.005, S E=.008$, $t=.621, p=.535, C I[-.011, .021]$. Next, when controlling for conscientiousness, the association between sexual desire and charisma was significant, $b=.058, S E=.014, t=4.264, p<.001$, $C I[.031, .085]$, while the association between conscientiousness and sexual desire was nonsignificant, $b=.003, S E=.011, t=.312, p=.756, C I[-.017, .024]$. Following this, we found 
that the association between charisma and sexual desire was significant, $b=.061, S E=.014, t=$ $4.217, p<.001, C I[.033, .090]$, when controlling for the association between negative emotionality and sexual desire, $b=.002, S E=.006, t=1.060, p=.439, C I[-.009, .013]$. Finally, the association between charisma and sexual desire also remained significant, $b=.057, S E=$ $.014, t=4.080, p<.001, C I[.030, .085]$, when controlling for the association between openness and sexual desire, $b=.002, S E=.007, t=.386, p=.700, C I[-.011, .016]$.

\section{Gender Analyses}

In our Study 1, we did not find a significant gender moderation between charisma and sexual satisfaction, sexual desire, or sexual communal strength. We do see a significant main effect such that men report more sexual communal strength, $b=.51, S E=.07, t=7.155, p<$ $.001, C I[.372, .653]$, compared to women, but no other gender differences.

In our Study 2, gender did not significantly moderate the association between one's own charisma (or partner's charisma) and daily sexual desire, sexual satisfaction, or sexual communal strength. However, we do see a significant main effect such that men report greater sexual desire, $b=.59, S E=.13, t=4.737, p<.001, C I[.349, .838]$, compared to women, but no other gender differences.

\section{Attachment Analyses}

Attachment style was measured in our first study using the Experiences in Close Relationships-Short Form (ECR-S; Wei et al., 2007). The ECR-S is a 12-item scale with two subscales, anxiety and avoidance. All the items are measured on a 7-point Likert scale $(1=$ "Strongly disagree", 7 = "Strongly agree"), and there are four reverse-scored items. An example of an anxiety subscale item includes "I need a lot of reassurance that I am loved by my partner" $(\alpha=.70, C I[.646, .739], \Omega=.71, C I[.666, .751], M=20.67, S D=6.38)$. An example of an 
avoidance subscale item includes "I want to get close to my partner, but I keep pulling back" ( $\alpha$ $=.83, C I[.802, .856], \Omega=.83, C I[.756, .858], M=14.05, S D=6.07)$.

This measure was used to control for people's comfort with closeness and independence in relationships (i.e., their attachment anxiety and avoidance). It is possible that charismatic people are lower in both attachment anxiety $(r=-.12, \mathrm{p}<.05)$ and avoidance $(r=-.26, \mathrm{p}<.01)$ and attachment is associated with sexual satisfaction and desire. The association between charisma and sexual satisfaction remained significant, $b=.059, S E=.017, t=3.529, p<.001$, $C I[.026, .092]$, while controlling for attachment anxiety, $b=-.022, S E=.011, t=-2.108, p<.05$, $C I[-.043,-.002]$. However, the association between charisma and sexual satisfaction was marginal, $b=.028, S E=.016, t=1.777, p=.076, C I[-.003, .059]$, when controlling for attachment avoidance, $b=-.094, S E=.011, t=-8.604, p<.001, C I[-.115,-.072]$. The association between charisma and sexual desire remained significant, $b=.062, S E=.013, t=$ 4.675, $p<.001, C I[.036, .089]$, while controlling for attachment anxiety, $b=.022, S E=.009, t=$ $2.612, p<.01, C I[.006, .039]$. Furthermore, the association between charisma and sexual desire also remained significant, $b=.041, S E=.014, t=3.063, p<.01, C I[.015, .068]$, while controlling for attachment avoidance, $b=-.046, S E=.009, t=-4.970, p<.001, C I[-.064,-.028]$.

\section{Narcissism Analyses}

Narcissism was measured in our first study using the narcissism subscale in the Short Dark Triad (SD3; Jones \& Paulhus, 2014). The narcissism subscale of the SD3 is a 9-item subscale that are measured using a 5-point Likert scale $(1=$ "Disagree strongly", $5=$ "Agree strongly"), and there are three reverse-scored items. Example items include "People see me as a natural leader" and "I know that I am special because everyone keeps telling me so." ( $\alpha=.75$. $C I[.710, .783], \Omega=.75, C I[.710, .786], M=22.53, S D=5.52)$. 
When controlling for narcissism, the association between charisma and sexual satisfaction remained significant, $b=.075, S E=.019, t=4.002, p<.001, C I[.038, .111]$, while the association between narcissism and sexual satisfaction was nonsignificant, $b=-.008, S E=$ $.014, t=-.558, p=.577, C I[-.035, .019]$. Furthermore, when looking at the association between charisma and sexual desire, after controlling for narcissism, this remained significant, $b=.045$, $S E=.015, t=3.024, p<.01, C I[.016, .075]$, while the association between narcissism and sexual desire was nonsignificant, $b=.021, S E=.011, t=1.861, p=.063, C I[-.001, .042]$.

\section{Tables}

\section{Table 1}

Demographic Statistics of Study 1 and 2.

\begin{tabular}{|c|c|c|c|c|}
\hline \multirow[t]{2}{*}{ Demographic } & \multicolumn{2}{|c|}{ Study $1(N=413)$} & \multicolumn{2}{|c|}{ Study $2(N=121$ couples $)$} \\
\hline & $M$ or $n$ & SD or \% & $M$ or $n$ & SD or \% \\
\hline Age (years) & 36 & 11.3 & 32.6 & 10.2 \\
\hline Relationship Length (years) & 11.8 & 10.3 & 8.5 & 8.4 \\
\hline \multicolumn{5}{|l|}{ Gender } \\
\hline Female & 290 & 70.2 & 124 & 51.2 \\
\hline Male & 115 & 27.8 & 115 & 42.5 \\
\hline Other & 6 & 1.5 & 3 & 1.2 \\
\hline \multicolumn{5}{|l|}{ Relationship status } \\
\hline Dating & 59 & 14.3 & 3 & 1.2 \\
\hline Cohabiting & 88 & 21.3 & 71 & 29.3 \\
\hline Common-law & 25 & 6.1 & 33 & 13.6 \\
\hline
\end{tabular}




$\begin{array}{lcccc}\text { Engaged } & 215 & 52.1 & 113 & 46.7 \\ \text { Married } & 19 & 4.6 & 19 & 7.9 \\ \text { Other or did not specify } & 7 & 1.7 & 3 & 1.2\end{array}$

Ethnicity

$\begin{array}{lcccc}\text { White } & 348 & 84.3 & 158 & 65.3 \\ \text { Black } & 9 & 2.2 & 11 & 4.5 \\ \text { Asian } & 21 & 5.1 & 38 & 15.7 \\ \text { Latin American } & 12 & 2.9 & 10 & 4.1 \\ \text { Other or did not specify } & 23 & 5.6 & 25 & 10.3\end{array}$

Sexual Orientation

$\begin{array}{lcccc}\text { Heterosexual } & 336 & 81.3 & 197 & 81.4 \\ \text { Bisexual } & 41 & 9.9 & 22 & 9.1 \\ \text { Gay or Lesbian } & 7 & 1.7 & 8 & 3.3 \\ \text { Other or did not specify } & 29 & 7 & 15 & 6.2\end{array}$

Note. $M$ and $S D$ represent mean and standard deviation, respectively. 


\section{CHARISMA AND SEXUAL QUALITY IN RELATIONSHIPS}

Table 2

Means, standard deviations, and correlations with confidence intervals

\begin{tabular}{|c|c|c|c|c|c|c|c|c|c|c|c|c|c|c|}
\hline Variable & $M$ & $S D$ & 1 & 2 & 3 & 4 & 5 & 6 & 7 & 8 & 9 & 10 & 11 & 12 \\
\hline 1. Age & 36.10 & 11.42 & & & & & & & & & & & & \\
\hline 2. Rel Duration & 11.79 & 10.34 & $.79 * *$ & & & & & & & & & & & \\
\hline 3. Charisma & 21.98 & 4.07 & .08 & .08 & & & & & & & & & & \\
\hline 4. PP Charisma & 23.19 & 4.48 & $-.12 *$ & -.09 & $.25 * *$ & & & & & & & & & \\
\hline 5. Sex Des & 6.85 & 2.20 & $-.25 * *$ & $-.25 * *$ & $.22 * *$ & $.27 * *$ & & & & & & & & \\
\hline 6. Sex Sat & 28.79 & 6.80 & -.08 & -.04 & $.19 * *$ & $.28 * *$ & $.42 * *$ & & & & & & & \\
\hline 7. SCS & 16.53 & 4.20 & -.04 & -.04 & $.19 * *$ & $.32 * *$ & $.58 * *$ & $.35^{* *}$ & & & & & & \\
\hline 8. CS & 82.92 & 13.84 & $.17 * *$ & $.17 * *$ & $.11 *$ & $.23 * *$ & $.24 * *$ & $.36 * *$ & $.46^{* *}$ & & & & & \\
\hline 9. Extraversion & 36.07 & 8.54 & $.15^{* *}$ & $.13 *$ & $.71 * *$ & $.15^{* *}$ & $.22 * *$ & $.23 * *$ & $.20 * *$ & .07 & & & & \\
\hline 10. Agreeable & 45.19 & 6.99 & $.24 * *$ & $.19 * *$ & $.33 * *$ & $.13 *$ & $.10 *$ & $.17 * *$ & $.16^{* *}$ & $.31 * *$ & $.22 * *$ & & & \\
\hline 11. Conscientious & 37.34 & 5.27 & $.13^{*}$ & $.14 * *$ & $.15^{* *}$ & $.11 *$ & .05 & .07 & .06 & $.16^{* *}$ & $.26 * *$ & .08 & & \\
\hline 12. Neg Emotionality & 35.93 & 10.51 & $-.26 * *$ & $-.17 * *$ & $-.37 * *$ & $-.10 *$ & -.06 & $-.12 *$ & -.10 & -.05 & $-.49 * *$ & $-.29 * *$ & $-.24 * *$ & \\
\hline 13. Openness & 45.34 & 8.32 & .09 & .03 & $.28 * *$ & $.10 *$ & .08 & .01 & $.21 * *$ & $.20 * *$ & $.28 * *$ & $.29 * *$ & .08 & $-.14 * *$ \\
\hline
\end{tabular}


Note. $M$ and $S D$ represent mean and standard deviation, respectively. PP = Perceived Partner, SCS = Sexual Communal Strength, CS $=$ Communal Strength. $*$ indicates $p<.05 . * *$ indicates $p<.01$. 


\section{CHARISMA AND SEXUAL QUALITY IN RELATIONSHIPS}

Table 3

Means, standard deviations, and correlations with confidence intervals for Study 2

\begin{tabular}{lrrlllll}
\hline Variable & $M$ & $S D$ & 1 & 2 & 3 & 4 & 5 \\
\hline 1. Age & 32.63 & 10.17 & & & & & \\
2. Rel Duration & 8.13 & 8.40 & $.76^{* *}$ & & & & \\
3. Charisma & 23.58 & 4.40 & .01 & -.01 & & & \\
4. Daily Sex Sat & 27.72 & 8.42 & $.09^{* *}$ & $.06^{* *}$ & $.12^{* *}$ & & \\
5. Daily Desire & 4.80 & 1.82 & $.06^{* *}$ & $.04^{* *}$ & $.08^{* *}$ & $.44^{* *}$ & \\
6. SCS & 17.11 & 3.71 & -.01 & -.00 & $.14^{* *}$ & $.17^{* *}$ & $.25^{* *}$ \\
\hline
\end{tabular}

Note. $M$ and $S D$ represent mean and standard deviation, respectively. $\mathrm{SCS}=$ Sexual Communal Strength. * indicates $p<.05 . * *$ indicates $p<.01$. 